\title{
Architecture_MPS
}

\section{Locative Media and Sociability: Using Location-Based Social Networks to Coordinate Everyday Life}

Michael Saker, ${ }^{*, 1}$ Jordan Frith ${ }^{2}$

How to cite: Saker, M., Frith, J. 'Locative Media and Sociability: Using LocationBased Social Networks to Coordinate Everyday Life.' Architecture_MPS, 2018, 14(1): 1. DOI: https://doi.org/10.14324/111.444.amps.2018v14i1.001.

Published: 01 September 2018

\section{Peer Review:}

This article has been peer reviewed through the journal's standard double blind peer-review, where both the reviewers and authors are anonymised during review.

\section{Copyright:}

(C) 2018, The Author(s). This is an Open Access article distributed under the terms of the Creative Commons Attribution License (CC-BY) 4.0 https://creativecommons.org/licenses/by/4.0/, which permits unrestricted use, distribution and reproduction in any medium, provided the original author and source are credited • DOI: https://doi.org/10.14324/111.444.amps.2018v14i1.001.

\section{Open Access:}

Architecture_MPS is a peer-reviewed open access journal. 


\title{
Amps
}

\section{Title: Locative Media and Sociability: Using Location-Based Social Networks to Coordinate Everyday Life}

\author{
Author: Michael Saker, ${ }^{1}$ Jordan Frith ${ }^{2}$
}

Architecture_media_politics_society. vol.14, no.1.

September 2018

Affiliation: ${ }^{1}$ City, University of London, ${ }^{2}$ University of North Texas

\begin{abstract}
Foursquare was a mobile social networking application that enabled people to share location with friends in the form of "check-ins." The visualization of surrounding known social connections as well as unknown others has the potential to impact how people coordinate social encounters and forge new social ties. While many studies have explored mobile phones and sociability, there is a lack of empirical research examining location-based social network's (LSBNs) from a sociability perspective. Drawing on a dataset of original qualitative research with a range of Foursquare users, the paper examines the application in the context of social coordination and sociability in three ways. First, the paper explores if Foursquare is used to organize certain social encounters, and if so, why. Second, the paper examines the visualization of surrounding social connections and whether this leads to "serendipitous encounters." Lastly, the paper examines whether the use of Foursquare can produce new social relationships.
\end{abstract}

\section{Keywords}

coordination, Foursquare, LBSNs, location-based social networks, locative media, sociability, social media

DOI: 10.14324/111.444.amps.2018v14i1.001, ( 2018 , The Authors. This is an Open Access article distributed under the terms of the Creative Commons Attribution License, which permits unrestricted use, distribution, and reproduction in any medium, provided the original author and source are credited. 


\title{
Title: Locative Media and Sociability: Using Location-Based Social Networks to Coordinate Everyday Life
}

\author{
Authors: Michael Saker, Jordan Frith
}

Architecture_media_politics_society. vol.14, no. 1 .

September 2018

\section{Introduction}

Digital media technologies increasingly affect how people understand and interact with their environment. As Townsend ${ }^{1}$ prophetically suggested, "portable digital communication tools . . . will undoubtedly lead to fundamental transformations in individuals' perceptions of self, and the world, and consequently the way they collectively construct that world." One of the main contributors to the shift Townsend predicted was the mobile web. The mobile web allows people to engage with digital and location-based information on the move. Consequently, the city has become "a hybrid of the physical and the digital." 2 When considered alongside smartphones and location-based social networks (LBSNs), the mobile web has the potential to affect how people engage with both their surroundings and each other. ${ }^{3,4,5,6}$ This potential can be seen in the LBSN Foursquare.

Foursquare was developed by Dennis Crowley and Naveen Selvadurai in late 2008 before being launched at the South by Southwest (SxSW) festival in 2009. Since its unveiling, the application has changed considerably. In 2014, Foursquare realigned, focusing on place-based suggestions and navigation. The check-ins that are the focus of this article were moved to a separate application: Swarm. ${ }^{7}$ Prior to this realignment, Foursquare functioned in a social, locational, playful, and archival manner. It is this original version of Foursquare that is the focus here. However, most of the data examined below is equally applicable to the newer Swarm application.

Foursquare (and now Swarm) enabled people to form networks through the application and check in to share their location with friends. People could also use Foursquare to explore place because preceding check-ins were algorithmically employed to offer users personalized place-based suggestions. Similarly, other users left "tips" that became locational digital traces of experience. Concerning play, Foursquare effectively turned ordinary "life into a 


\section{Amps}

game" 8 by awarding points, mayorships, and badges for check-ins. Lastly, Foursquare worked as a "memory tool that people [could] use to archive their past mobility." $9,10,11$

Foursquare has been widely studied in mobile communication literature. However, with the exception of Frith's ${ }^{12}$ work, extant research has not fully addressed how people use the application to engage in new forms of social interaction or "sociability", as we refer to it throughout this article. "Sociability" in this context includes making social arrangements, engaging in impromptu social encounters, and forging new social connection. As Bertel ${ }^{13}$ points out, research on LBSNs and sociability "has mainly been theoretical, critical reviews or interpretations of previous empirical work." Given the incorporation of locative mechanics in more mainstream social-networking sites (SNSs), such as Facebook and Twitter, there is an exigency for additional studies that explore these issues. With this in mind the article expands upon the social potential of Foursquare, drawing on original research to address three overarching questions: (1) is Foursquare used to organize social encounters, and if so, why? (2) Does the visualization of surrounding social connections lead to "serendipitous encounters" with known others? (3) Does the use of Foursquare lead to new social relationships?

To explore these issues further, we first review literature on mobile communication and social coordination. We then describe our methodological approach before moving on to data analysis and concluding with a discussion of our findings. Our chief aim is to shed light on the social practices of Foursquare users and in so doing build upon contemporary understandings of the diverse uses of locative media.

\section{From Time-Based to Space-Based Social Coordination}

For much of the twentieth century, examinations of social coordination focused on the temporal dimension. This approach was based on the works of Georg Simmel, who argued the displaced nature of social connections in the metropolis meant that individuals had to adopt time-based systems of social coordination in order for them to function smoothly. For Simmel ${ }^{14}$ the "universal diffusion of pocket watches" underlined this situation. Coordinating sociability in the metropolis accordingly involved "complex systems and inflexible time." 15 People had to be "punctual" in order for social arrangements to work as it was not yet possible to rearrange things on the move. ${ }^{16}$

The adoption of the mobile phone shifted understandings of temporality, altering practices of urban coordination. ${ }^{17,18,19}$ ) The finer details of social arrangements can now be negotiated in transit, just as people have the option of remaining in "perpetual contact" with their social circles regardless of physical proximity. ${ }^{20,} 21,22$ For Ling and $\mathrm{Yttri}^{23}$ this "microcoordination," as they refer to it, has transformed the spatial and temporal constraints surrounding social coordination..$^{24,25}$ 


\section{Amps}

These new forms of "on the fly" coordination are important because they effectively "soften" the power of mechanical time. ${ }^{26}$ A corollary to this development is the mollification of Simmel's suggested need for "punctuality". Practices of microcoordination have spatial impact as well, as distance is similarly reduced when individuals no longer have to call places (landline phones), but can instead call people. ${ }^{27,} 28,29$ Mobile phones are therefore implicitly understood to reduce the importance of space. ${ }^{30,31,32}$ This suggestion resonates with early scholarly criticisms of mobile telephony and environmental dislocation, ${ }^{33,34,35}$ as well as contemporary studies that explore these devices in the context of pedestrian distraction..$^{36}$

In contrast to earlier mobile phone scholarship that focused on how people became distracted from their surroundings, and in so doing, it could be argued, momentarily reduced the significance of their location, the rise in locative media can be seen as reinstating the importance of physical location. ${ }^{37}$ For de Souza e Silva and Sutko ${ }^{38}$ mobile interfaces now function as "technological filters" that help "users manage interactions with city space." As Frith ${ }^{39}$ suggests, "[increasingly], individuals use mobile applications to share their location with friends" and to see which social connections are nearby. From this position, far from removing the question of place from sociability, the mobile phone in these instances is "firmly embedded in what it means to experience place, ${ }^{40}$ just as it is entangled in communal practices. Humphreys'41 study of the pioneering mobile social network Dodgeball is a good case in point.

Active in the mid 2000s, Dodgeball allowed users to share their location with a select group of existing friends. Individuals would text their location to a central service, which would then send this information to recipients in a series of text messages. Humphreys ${ }^{42,43}$ found that Dodgeball users frequently changed their movements through the city if they realized friends were nearby, just as they experienced unfamiliar environments as being in some way more familiar. Elaborating on this further, Humpreys ${ }^{44}$ identifies a process she refers to as social molecularization. This process occurs when users "experience and move through the city in a collective manner," ${ }^{45}$ precisely because of their interaction with this mobile social network. Yet this isn't to suggest that public space lacked sociability outside of Dodgeball. Rather, what Humphreys is positing is the social molecularization configured through Dodgeball is different in two ways. First, users no longer have to discuss location, as this is textually communicated through the interface itself. Second, locational information is detailed in real time, allowing users to make decisions about their movements as and when they receive such information. "Together these two differences can bring about momentum in using and responding to Dodgeball checkins." ${ }^{46}$ In effect, then, by enabling users to visualize where their friends were in relation to their locative position, this spatial awareness worked alongside "the clock as a medium for coordinating meetings in space". ${ }^{47}$

Dodgeball has since been replaced by more technologically advanced LBSNs that use both the mobile Web and the GPS functionality of smartphones. 


\section{Amps}

These applications provide new opportunities for people to coordinate socially through the sharing of location and the visualization of space. The increase in location sharing and the use of location in mobile applications more generally has been met with a growth in the literature on these applications. ${ }^{48,49,50,51,52,53,54,55,56}$ Locative applications and mobile social networks have been shown to alter urban mobilities, ${ }^{57,58}$ imbue life with a sense of play, ${ }^{59,60,61}$ and more broadly impact perceptions of mobile media. ${ }^{62}$

For our purposes, what is significant about the corpus of locative media is that it has "focused on the impact of LBSNs on space and place." ${ }^{63}$ While there are notable studies that have extended place-based discussions to other areas, conceptualizing Foursquare through a post-phenomenology of place, ${ }^{64}$ and examining the marking of location as a modality of self presentation, ${ }^{65,66,67}$ aside from Frith's ${ }^{68}$ work on Foursquare, research that approaches the application from a sociability perspective is lacking. Similarly, there is a lack of empirical studies that examine Foursquare's potential to either enable "serendipitous encounters" or develop new social ties.

In contrast, a body of work surrounds SNSs and sociability. ${ }^{69,70,71,72,73,74}$ ) Research in this area has shown how SNSs can facilitate social relationships, ${ }^{75,76,77,78}$ maintain existing social connections,${ }^{79}$ ), and forge new friendships. ${ }^{80}$ It is our aim to address this gap in the literature on locative media by examining Foursquare in the context of sociability.

\section{Methodology}

The data used in this paper is based on semi-structured interviews with a range of Foursquare users. It was never our intention to make broad generalizations about the application, but rather gather rich information on LBSN adoption in everyday lives. This study therefore focuses on "how ordinary people" using Foursquare "observe and describe their lives," 81 paying close attention to what "meanings" individuals attribute to their given social situation.

As Horrocks and King ${ }^{82}$ note, "[researchers] seek to recruit participants who represent a variety of positions in relation to the research topic, of a kind that might be expected to throw light on meaningful differences in experience." Following approval by the University Ethics Committee, a diverse range of Foursquare users were recruited for this study. Recruitment involved Foursquare, Twitter, Facebook, Gumtree, leaflets and emails, with Twitter being by far the most successful of these approaches. This is because it allowed us to identify Foursquare users who would then 'retweet' details of our project to larger groups of people. In all instances, individuals interested in the study received a "participant information sheet." This sheet detailed the rationale for the project, what taking part would encompass, and how collected data would be used. Those who still wanted to be involved then had to sign a consent form acknowledging that they had fully read the "participant information sheet," were happy for their data to be used for the purposes of this study, and that they understood they could withdraw from the study at 
any time. Participant anonymity and confidentiality were protected during and after the project using pseudonyms, while the ensuing data was securely stored, to ensure that it was not disclosed to public/unauthorized individuals.

During the summer of 2012, twenty-two Foursquare users were interviewed, all of whom resided in the south east of Britain. This area was chosen so face-to-face interviews could be conducted where possible. In sum, twenty participants were interviewed in person and two by Skype. Participants included seventeen men and five women. Ages ranged from nineteen to sixtyfive, with the mean age being thirty-two. Interviews were semi-structured and focused on social coordination and sociability. For the most part interviews lasted approximately one hour. This is because half an hour or more is arguably needed in order for the information to be valuable, whereas "anything going much over an hour may be making unreasonable demands on busy interviewees, and could have the effect of reducing the number of persons willing to participate." 83 The vast majority of interviews took place in venues participants regularly checked-in to. All interviews were recorded and then transcribed by hand.

As Klandermans and Staggenborg ${ }^{84}$ suggest, "[in] semi-structured interviewing, analysis and interpretation are ongoing processes." Accordingly, the "interpretation of initial interviews can ... reshape the direction of the study." 85 The first five interviews were piloted to experiment and develop the various verbal probes required to explore the paths emerging amidst the assorted social uses of Foursquare. This approach importantly helped establish the questions that were most conducive to our study. For Horrocks and King, ${ }^{86}$ when exploring different approaches to analysis, "one distinction that is often made is between approaches that are strongly focused on language and those that are more concerned with the content of what the participant has to say. Congruently here, and as evidenced by the data sought, this research is principally interested in comprehending how participants use and understand Foursquare from their own perspective, and in their own words. To this end, from the offset it was our intention to become fully immersed in the material gathered. Analysis therefore commenced with the careful reading of full interview transcriptions, highlighting material that was applicable to this project. An interpretive stage was subsequently employed to draw out meaning from our gathered data. These interpretations were then hierarchically ordered in terms of their significance to the exigency of this study."

\section{Findings}

\section{Social coordination}

Foursquare has promoted the potential for check-ins to positively impact social coordination. Our research found that while participants used Foursquare in a variety of social situations, there was a significant emphasis on interactions in which participants were not sure what time they would be available to meet with friends. 


\section{Amps}

We used to do it at work, especially at the media agency, because there are a lot of people using it. People would finish work at different times, depending on what department they were in, so they would maybe go off to a pub or a restaurant and then say, come find us later. So instead of picking up the phone and calling them, you would just find the person, see where they were. As long as they had checked-in you would know that they were at that particular place. So if they were going for a drink or to a restaurant, you wouldn't have to worry about rushing out the door or following them, you can just wait until they checked-in, and then meet them there. (Dennis)

I was going to meet up with a friend and I didn't know where I was going to be and I just said, check where I am on Foursquare and you'll know where I am. (David)

This spatial sentience meant that Dennis no longer had to "rush out" after colleagues at the end of the day. He could instead choose when he wanted to join them, at a time and place that was ostensibly convenient to him. To be clear, although the ensuing interactions in both examples did take place at a certain time, they weren't solely organized through time, but also the visualization of space.

Our data shows that the vast majority of these occurrences involved groups of work colleagues congregating at the end of the week. These gatherings frequently involved participants visiting a number of different venues, with both known and unknown others arriving at various times. Some participants commented that prior to Foursquare, such social events were far more challenging to organize because people were less likely to hear their phone ringing as the evening went on, which then made it increasingly difficult for people to find out where everyone else was if they were "late." In most instances, Foursquare's communicative affordances worked best in situations predicated on a prior agreement to meet up that involved multiple people. As multiple participants explained, check-ins were more successful as a form of semi-mass communication than one-on-one interpersonal communication. In dyadic interpersonal situations, texting or simple messaging was likely more effective.

In most social situations revealed in our data, the majority of participants did not actively contact friends to alter arrangements in transit, but rather used Foursquare to see where friends were. Significantly then, Foursquare provided the possibility of social encounters without the responsibility. An important part of this process is accordingly the reduced obligation to arrive at a specific place at a specific time. Participants who used Foursquare to meet with work colleagues appreciated the fact these gathering felt less compulsory than they would through other communicative means. In this vein, several participants commented that the use of Foursquare gave them additional ability to change their mind because they did not have to make a binary decision at a specific time. This phenomenon was underlined by participants who had decided not to meet with colleagues, but then reversed their decision when either their mood or the location of the group changed. 


\section{Amps}

\section{Serendipitous encounters}

Foursquare heavily promoted the "serendipitous encounters" that can occur through location sharing. These encounters take place when one person is able to see a friend has checked-in nearby, and then meets with them. We found this did occasionally happen with our participants:

A friend Dave, he lives in Woking near me, and he just happened to be in London one day, but he wasn't planning on staying out, he was just going to go straight home, and I'd been out with work colleagues and was walking back to the train station and saw he was there, and it was sort of on the way, so I just popped in. (Dennis)

My school was in Petersfield and I saw some old people who used to go to that school live nearby, and sometimes they check-in and I'll say, hey do you want to come in for a coffee. I did that a few times. In fact, I did that pretty much every week People come by and visit. So yeah, that's been really useful. I imagine it will be good at Surrey, as a lot of my friends are quite close to Surrey, so a lot of them will probably be nearby. (Mark)

This kind of meeting is notably different to the social interactions produced by older mobile phones. The ability to visualize where friends are located allowed more impromptu social encounters to transpire, stemming from a different kind of connectedness. At the same time, however, and perhaps more significantly, our research also shows that these encounters were rarely welcomed. This is important, given the positive framing of such happenstances by Foursquare.

I've had a few funny moments in that sense, when I've arrived somewhere, checked-in and it has said your friend Ben is here, okay, and I've looked up and he's walked around the corner in the pub. So it has mainly been things like that. It has mainly been randomly bumping into people in the same location. If I check-in somewhere now, if there are other people there, I will see if I know them. (Doug)

Was the experience improved because of Foursquare? (Researcher)

Well I probably wouldn't have known he was there. I mean, okay, he happened to walk around, but I was saying to my wife, it's really weird, it's saying a friend of mine is here and when I looked he was checked-in a couple of minutes ago, and I was like, he must still be here, and then he came around the corner. So that was kind of weird. (Doug)

So did you just say 'hi' and then carry on with what you were doing? (Researcher)

Yes, because I was having dinner with my family and he was having dinner with his family. (Doug)

This predicament illuminates that just because Foursquare can produce "serendipitous encounters," it does not necessarily follow that these meetings 


\section{Amps}

are desirable or that participants know what social signs apply in these situations. For many participants, the possibility of such meetings were not only unwanted, but seen as markedly awkward.

It is quite awkward because if someone isn't that close you wouldn't do that kind of thing because you would feel you are stalking someone. (Robbie)

This research also found that the visualization of social space through Foursquare was used by some participants to actively avoid certain social situations. Again, this goes against the initial publicity surrounding the application.

So are your friends on Foursquare close-friends? (Researcher)

Yes, they were, then since the merger with American Express I've had colleagues requesting it and obviously you can't really decline, so now it has changed slightly. But you can get around it, you can check-in at all the places you go, but when you don't want to tell certain people you can keep checking-in and it gets missed. (David)

Do you mean you are using the 'private' function? (Researcher)

No, what I mean is you can check-in to all the places you've been during the day, but just miss the places out that you don't want them to see. Then those people see your other check-ins and just assume you are around that area. It is like using this whole kind of openness to actually be more private. (David)

In this example, David had accepted various friend requests from individuals he wasn't particularly close with. As a result, he then used the spatial affordance of Foursquare to avoid these people without appearing rude. There were other instances of participants similarly using the visualization of space to actively evade people. This shows that the coordination of social interaction through the visualization of space is not always done with social ends in mind. Just as locative media can increase the likelihood of "serendipitous encounters," it can also produce new tactics for avoiding such encounters.

Ultimately, the challenges of dealing with serendipity or even avoiding serendipity shows an important fact about the social nature of the check-in: as a relatively new form of social communication, our research revealed an established set of social norms had not arisen governing location sharing. People repeatedly expressed uncertainty about what to do when someone checked-in nearby, and as discussed earlier, they begrudgingly would sometimes meet up or go out of their way to avoid making a connection. Our data suggests that it will be interesting for future researchers to examine if a more established set of social norms does coalesce around the serendipitous encounter enabled by LBSNs. 


\section{Amps}

\section{New relationships}

Foursquare uses an eponymous interface, which means participants can see unknown others who have checked-in at the same place. Our data shows that the ability to visualize nearby Foursquare users did lead some participants to develop new friendships. For the most part this was the case for participants who were more interested in the gaming side of the applications. There were several instances of participants who were fighting over a certain mayorship with an unknown other, which then provided space-based opportunities for social connections.

Like this guy Ian, I had no idea who he was, then I got a message saying he'd stolen my mayorship, and then I saw his Twitter, and tweeted him to say, give that back, and then you just get chatting, and it has got to the point where we've gone for a drink. (Dennis)

It's largely banter. Particularly the messages Foursquare sends you, like Jamie just stole the mayorship from you. You're not going to let that stand! So I took it from him and wrote, in your face. (Richard)

When these situations did occur, interestingly the ensuing communication frequently took place through Twitter, as many participants had linked social media accounts and were therefore aware of accompanying usernames and the like.

I only know him because he and I were vying for the 'mayorship' of Woking station for a while. I have not met him in person, because we just keep on not getting around to it, and literally the only reason we know each other at all is because for about a period of two months, we would alternate 'mayorships' about once or twice a week. (Adrian)

So how did you two get in contact with each other? (Researcher)

I think we probably both had it set to 'tweet' when we gained a 'mayorship', and so we started chatting on Twitter as a result, just a, ha-ha better luck next time, kind of thing, and then he sent me a Foursquare friend request at some point and I thought why not? (Adrian)

I've got my Foursquare tied in with Twitter, so my check-in comes up as a status. (Ben)

Another reason some participants gave for using Twitter to form these connections was that communicating through Foursquare felt too personal, whereas Twitter provided a safer more open forum to jovially "brag" about the acquisition of "mayorships". In terms of these social connections then, they were oftentimes symptomatic of participants using the application for reasons revolving around play. In other words, participants were not actively using Foursquare to make new friends per se, but rather engaging with space and place in the context of a game. This playful engagement then became a conduit through which new social ties were forged. 


\section{Amps}

This research shows that just as the playful affordances of Foursquare led some participants to make new friends, other participants developed additional social ties through the active community that surrounds the application. This was repeatedly the case with participants who identified themselves as being "heavy users."

I've definitely made some friends that I would meet up with in real-life if I were well enough. It's just nice. There are a lot of my friends online that sort of don't understand it, don't get it, who are not particularly interested in it, so it is nice to have that little circle of people that I can literally rabbit about Foursquare with all day. I am bonkers about Foursquare. I don't know why I've got the enthusiasm that I have? I just appreciate it so much, as it has changed my life, it has got me out the house so much more than what I used to. So I've just got this big appreciation for it. (Sarah)

For Sarah, Foursquare significantly allowed her to socialize with a "circle of people" that understood and appreciated her obsession with this LBSN. In several comparable incidences, participants did not necessarily make friends with other users through the Foursquare application itself, but through their involvement with unofficial Foursquare fan sites and corresponding Twitter accounts. Significantly, the "circle of people" Sarah mentioned was geographically dispersed, which was a common occurrence for participants who had developed social ties with the surrounding community. Mark touches on this point in the following extract.

A lot of them are based all over England. There's not really many near me. The closest would be Drew, because he lives in Woking. So we've crossed paths many times. I've had a few close misses with him. I was there to see Derren Brown and he was checked-in at a pub nearby and I didn't notice, I wasn't paying attention you see, and he was like, I could have seen you then, and I was like, poor me. (Mark)

On the whole, our research found that participants who had made friends with other Foursquare users in this manner seldom then met these people in person. Instead, Foursquare provided a network of online contacts that participants would then engage with to "pass the time." It should be noted here that this form of engagement was again only evident with participants who classified themselves as "heavy users." In these instances, it was a mutual appreciation of Foursquare that provided a common ground for participants and "unknown others" to bond over.

\section{Discussion}

de Souza e Silva and Sutko ${ }^{87}$ propose that as the use of locative media gains popularity, the visualization of space rather than time will increasingly 


\section{Amps}

mediate social life. To a certain extent our research supports this assertion. Much like in Frith's study, the visualization of space to coordinate certain gatherings "was generally limited to a few specific social situations ${ }^{88}$ in which many people may be congregated in a limited physical area." 89 Repeatedly these situations involved evenings out with work colleagues, as opposed to close friends. Here Foursquare provided participants with the freedom to join these acquaintances when they wanted to without feeling obligated to appear at a specific time or place. In other words, the visual affordance of Foursquare effectively functioned to alleviate some of the social responsibility felt by participants who wanted to socialize on their own spatiotemporal terms, without fear of offending others. For those involved, these interactions could then unfold in a manner that felt more relaxed. This finding possibly extends Ling's ${ }^{90}$ earlier work on how the mobile phone lessened the importance of set times, showcasing how location-sharing becomes a more passive way to loosen social bonds and arrange gatherings.

The visualization of space alone, however, did not solely coordinate these encounters. Equally important was a previously established temporal understanding that get-togethers would be organized in this way and would occur within a certain window of time. A significant aspect of these "specific social situations" then, was an awareness of the underlying intent surrounding check-ins. ${ }^{91}$ Participants using Foursquare were cognizant that the marking of location within this context signified an invitation to "meet up". In this vein, and through a tacit agreement that a social encounter would take place at some time, Foursquare builds upon Ling and Yttri's ${ }^{92}$ notion of "micro-coordination." In contrast to older mobile telephony and sociability, however, the visualization of space meant that neither a specific time nor place needed to be negotiated in transit. ${ }^{93,94}$ Instead, participants could establish where people were without actively engaging others in dialogue. Accordingly, Foursquare similarly offers a mode of "social molecularization" 95 that accentuates the sociability of the city outside of this "human-body-device-sensor-software-data configuration," 96 one that is enabled through the spatial and temporal affordances of this assemblage. Consequently, and significantly, Foursquare doesn't simply "soften" time, ${ }^{97}$ but equally softens space.

The social sentience Foursquare permits also means there are now more opportunities for social encounters to occur that have not been previously arranged. While several participants spoke of their use of Foursquare having led to them socializing with people they otherwise wouldn't have, making their environment feel more social and echoing Humphreys' 98,99 finding regarding Dodgeball, for the most part "serendipitous encounters" with known others were rarely welcomed. Rather than being 'serendipitous' such meetings were experienced as being "inconvenient". How successful Foursquare was at coordinating social encounters was here predicated on there being some form of tacit agreement already in place, as touched on above, suggesting that an established set of social norms had not arisen surrounding the check-in. 


\section{Amps}

People instead repeatedly felt uncomfortable and did not know how to react when faced with the possibilities of serendipitous sociality. As Frith suggests

The different reasons people use Foursquare complicate the issues of sociability and collective mobile communication ... Some people who used Foursquare for more social reasons or as a way to catalogue their life only checked in to more interesting locations they wanted to highlight. But other users who saw Foursquare more as a game checked in everywhere. ${ }^{100}$

In alignment with Frith, ${ }^{101}$ our research found that participants would checkin for many reasons other than social coordination. Humphreys' ${ }^{102,} 103$ study of Dodgeball is again useful here. As she notes, "[social] interaction is a complex negotiation. The same information exchanged through Dodgeball could be used to facilitate meeting up as much as it could be used to avoid a particular person." 104 De Souza e Silva and Frith ${ }^{105}$ propose that mobile interfaces function as "technological filters" helping "users manage interactions with city space," and thus "cope with sensory overload." 106 This study supports such a position, both in terms of identifying places to engage with as well as avoid. For instance, some participants suggested that due to the different locations, timings, and people involved, organizing post-work events prior to Foursquare was an extremely hard task. By using Foursquare in this manner, participants were effectively able to "filter" out the spaces that weren't socially significant to them, while focusing on those that were. Similarly, participants were also able to use the application to filter out the social spaces they actively wanted to avoid. In these examples, the implicit openness of Foursquare was paradoxically used to curtail sociability and bolster privacy. David's concealment of his location through outdated check-ins is an interesting case in point, which raises some pressing questions around locative media and issues pertaining to social privacy, just as it casts a much needed light on locative media practices that are undertaken to hide one's locale. ${ }^{107}$

Importantly, checking-in on Foursquare requires an active process of engagement. Unlike some LBSNs, such as Swarm, Foursquare does not use real-time location tracking (it should be noted that this aspect of Swarm can be switched off by the user, and only general spatial coordinates are shared). In the context of Foursquare, people must search for nearby locations and then check in. The work of Papacharissi ${ }^{108}$ is helpful here for working through some of the issues users might face when choosing to disclose personal and locative data. While privacy, in Western nations at least, is considered a basic human right, new media technologies and concomitant companies are increasingly placing the onus on individuals to determine where this entitlement begins and ends. ${ }^{109}$ Running concurrently with this trend, monolithic companies such as Facebook and Google have been accused of breaking EU privacy law by effectively utilizing self-serving terms and conditions that implicitly implicate users in acts that contravene their 
own rights. As Papacharissi ${ }^{110}$ explains, "[companies] employ privacy and terms of user statements to outline how personal information provided will be used, so that in the event of users' complaints, companies are absolved of responsibility." Users of services such as Foursquare are therefore placed in a potentially difficult position where they must reconcile fears of surveillance with their desire to interact with locative applications. In this instance, the benefits of Foursquare evidently outweighed any apprehensions participants might have felt about who was accessing their data and why, with this LBSN being used in one instance as a viable way to remain hidden. In other words, while the sharing of location can have possible negative privacy aspects and lead to a kind of social "Big Brother" observation, in the context of this study the active process of the check-in also offered the ability to limit those effects. People tended to check in strategically, highlighting some places over others and sharing locations at times when they might be more willing to meet up. People rarely checked in from private places they did not want others to know about, in part because those places are unexciting to show off to others and in part because they have little chance of social serendipity.

Lastly, our study explored whether Foursquare led to new social relationships. To reiterate, it has been suggested "we might be witnessing a technological and social shift towards the ability for location-aware media to help build and connect with new ties." 111 This research found that Foursquare did lead to some participants developing new social ties. However, much like with SNSs, this practice wasn't a common occurrence among most participants ${ }^{112}$ but was instead reserved for those who were either heavily involved in the surrounding community or those with a deep interest in the gaming side of Foursquare. In terms of the former, for the most part new social ties were geographically dispersed and subsequently maintained online. In terms of the latter, participants who established new connections through locationbased play often did so because of a shared connection to a specific place or location.

\section{Limitations}

A limitation of this study is the gender imbalance of the participants involved. From the offset, it was notably more difficult to gain female participants than it was male participants. This, of course, could be the case for a number of reasons. It could be that the participants who helped establish contact with other participants early on had more male than female friends, and accordingly put us in touch with these users. Likewise, it could also be that female participants felt less comfortable meeting with researchers that they hadn't met before. Regardless of the reasons, future studies should examine questions of gender and locative media in more detail, as it would be hugely interesting to explore the potentially different ways men and woman employ locative applications to facilitate their social lives. Likewise, it would also be interesting to extend this research to other locales beyond the south east of the 


\section{Amps}

UK. Again, this could cast a meaningful light on the various ways in which location impacts how locative applications are configured and used.

\section{Conclusion}

This study has explored how people use Foursquare in the context of sociability, to coordinate social situations and develop new relationships. In doing so, our work readily contributes to research on how people use Foursquare to coordinate certain social interactions ${ }^{113}$ as well as forge new social ties. At the same time, this study also addresses gaps in the literature surrounding LBSNs and sociability using original research, which is frequently lacking in this field. ${ }^{114}$ As the use of locative media continues to increase ${ }^{115}$ as well as develop in new and perhaps wearable ways, ${ }^{116}$ there will be further opportunities for people to share their location, coordinate meetings, and create new social bonds. With this in mind, new social understandings will need to be developed around locative applications and the intentions behind the marking of one's location, because it is apparent check-ins mean different things to different people. While LBSNs and sociability are limited in scope now, new forms of locative media might lend themselves to a variety of different situations. Future studies should explore these issues in the context of specific LBSNs, paying close attention to their communicative affordances and the various social opportunities they might support.

\section{Notes}

1 Anthony Townsend, "Life in the Real-Time City: Mobile Telephones and Urban Metabolism," Journal of Urban Metabolism (2000):1.

2 Michiel de Lange and Martijn de Waal. "Owning the City: New Media and Citizen Engagement in urban Design," First Monday (2013): n.p, accessed October 26, 2017, doi:http://firstmonday.org/article/view/4954/3786.

3 Adriana de Souza e Silva, "From Cyber to Hybrid: Mobile Technologies as Interfaces of Hybrid Spaces, "Space and Culture 9, no. 3 (2006): 261-78.

4 Jordan Frith, "Splintered Space: Hybrid Spaces and Differential Mobility," Mobilities 7, no. 1 (2012): 131-49.

5 Jordan Frith, Smartphones as Locative Media (London: Polity Press, 2015).

6 Michael Saker and Leighton Evans, "Locative Mobile Media and Time: Foursquare and Technological Memory," First Monday 21, no. 2 (2016), accessed October 26, 2017, doi:http://dx.doi.org/10.5210/fm.v21i2.6006.

7 “About Us," Foursquare Corporation, accessed April 8, 2016, https://foursquare. com/about.

8 Jordan Frith, "Turning Life into a Game: Foursquare, Gamification, and Personal Mobility," Mobile Media \& Communication 1, no. 2 (2013): 248-62.

9 Jordan Frith, "Communicating Through Location: The Understood Meaning of the Foursquare Check-In," Journal of Computer-Mediated Communication 19, no. 4 (2014): 890-905. 
10 Jordan Frith and Jason Kalin, "Here, I Used To Be: Mobile Media and Practices of Place-Based Digital Memory," Space and Culture19, no. 1 (2016): 43-55.

11 Saker and Evans, "Locative Mobile Media and Time."

12 Frith, "Communicating Through Location," 890-905.

13 Troels Fibæk Bertel, “Why Would You Want To Know?' The Reluctant Use of Location Sharing via Check-Ins on Facebook among Danish Youth," Convergence 22, no. 2 (2016): 1.

14 Georg Simmel, "The Metropolis and Mental Life," in Simmel on Culture, ed. Mike Featherston and David Frisby (London: Sage, 1997), 177.

15 Kay W. Axhausen, John Urry, and Jonas Larsen, Mobilities, Networks, Geographies (Ashgate Publishing, Ltd., 2012), 59.

16 Georg Simmel, "The Metropolis and Mental Life," 177.

17 Ditte Laursen and Margaret H. Szymanski, "Where Are You? Location Talk in Mobile Phone Conversations," Mobile Media \& Communication 1, no. 3 (2013): 314-34.

18 Rich Ling, The Mobile Connection: The Cell Phone's Impact on Society (San Francisco, CA: Morgan Kaufmann, 2004).

19 Alexandra Weilenmann, “'I Can't Talk Now, I'm in a Fitting Room': Formulating Availability and Location in Mobile-Phone Conversations," Environment and Planning A 35, no. 9 (2003): 1589-1605.

20 Jon Agar, Constant Touch: A Global History of the Mobile Phone (Icon Books Ltd, 2013).

21 James E. Katz and Mark Aakhus, eds. Perpetual Contact: Mobile Communication, Private Talk, Public Performance (Cambridge: Cambridge: University Press, 2002).

22 Christian Licoppe, “'Connected' Presence: The Emergence of a New Repertoire for Managing Social Relationships in a Changing Communication Technoscape," Environment and Planning D: Society and Space 22, no. 1 (2004): 135-56.

23 Richard Ling and Birgitte Yttri, "10 Hyper-Coordination via Mobile Phones in Norway," in Perpetual Contact, 139-69.

24 Rich Ling, The Mobile Connection".

25 Richard Ling and Birgitte Yttri, "10 Hyper-Coordination,” 139-69.

26 Ibid.

27 Kay W. Axhausen, John Urry, and Jonas Larsen, Mobilities, Networks, Geographies, 59.

28 Rheingold, Howard and Anthony Weeks, Net Smart: How to Thrive Online (Cambridge, MA: MIT Press, 2012).

29 Barry Wellman, "Little Boxes, Glocalization, and Networked Individualism," in Computational and Sociological Approaches: Second Kyoto Workshop on Digital Cities, ed. Makoto Tanabe, Peter van den Besselaar, and Toru Ishida (Berlin, Heidelberg: Springer, 2003), 10-25.

30 Adriana de Souza e Silva and Jordan Frith, "Locational Privacy in Public Spaces: Media Discourses on Location-Aware Mobile Technologies," Communication, Culture \& Critique 3, no. 4 (2010): 503-25.

31 Jordan Frith, "Communicating Through Location," 890-905. 


\section{Amps}

32 Jordan Frith, Smartphones as Locative Media.

33 Chantal de Gournay, "12 Pretense of Intimacy in France," in Perpetual Contact, 193-205.

34 Kenneth J. Gergen, "The Challenge of Absent Presence," in Perpetual Contact, 227.

35 Katz and Aakhus, eds. Perpetual Contact.

36 Despina Stavrinos, Katherine W. Byington, and David C. Schwebel, "Distracted Walking: Cell Phones Increase Injury Risk for College Pedestrians," Journal of Safety Research 42, no. 2 (2011): 101-7.

37 Eric Gordon and Adriana de Souza e Silva, Net Locality: Why Location Matters in a Networked World (Malden, MA: John Wiley \& Sons, 2011).

38 Daniel M. Sutko and Adriana de Souza e Silva, "Location-Aware Mobile Media and Urban Sociability," New Media \& Society 13, no. 5 (2011): 809.

39 Frith, "Communicating Through Location", 890.

40 Larissa Hjorth, "Being Real in the Mobile Reel: A Case Study on Convergent Mobile Media as Domesticated New Media in Seoul, South Korea," Convergence 14, no. 1 (2008): 93.

41 Lee Humphreys, "Mobile Social Networks and Social Practice: A Case Study of Dodgeball," Journal of Computer-Mediated Communication 13, no. 1 (2007): 341-60.

42 Humphreys, "Mobile Social Networks and Social Practice, 341-60.

43 Lee Humphreys, "Mobile Social Networks and Urban Public Space," New Media \& Society 12, no. 5 (2010): 763-78.

44 Humphreys, "Mobile Social Networks and Social Practice, 341-60.

45 Ibid., 353.

46 Ibid.

47 Sutko and de Souza e Silva, "Location-Aware Mobile Media, 809.

48 De Lange, and de Waal. "Owning the City."

49 De Souza e Silva and Frith, "Locational Privacy in Public Spaces, 503-25.

50 Evans and Saker, Location-Based Social Media.

51 Frith, "Splintered Space,"131-49.

52 Jordan Frith, Smartphones as Locative Media.

53 Lee Humphreys and Tony Liao, "Foursquare and the Parochialization of Public Space," First Monday 18, no. 11 (2013).

54 Rich Ling and Scott W. Campbell, eds. The Reconstruction of Space and Time: Mobile Communication Practices (New Brunswick, NJ: Transaction Publishers, 2010).

55 Rowan Wilken, "Locative Media: From Specialized Preoccupation to Mainstream Fascination," Convergence 18, no. 3 (2012): 243-7.

56 Rowan Wilken and Gerard Goggin, eds. Mobile Technology and Place (London: Routledge, 2013).

57 Gordon and de Souza e Silva, Net Locality: Why Location Matters.

58 Saker and Evans, "Locative Mobile Media.

59 Frith, "Turning Life into a Game, 248-62.

60 Christian Licoppe and Yoriko Inada, "Geolocalized Technologies, LocationAware Communities, and Personal Territories: The Mogi Case," Journal of Urban Technology 15, no. 3 (2008): 5-24. 
61 Janne Lindqvist, Justin Cranshaw, Jason Wiese, Jason Hong, and John Zimmerman, "I'm the Mayor of My House: Examining Why People Use Foursquare - A Social-Driven Location Sharing Application," in Proceedings of the SIGCHI Conference on Human Factors in Computing Systems (ACM, 2011), pp. 2409-418.

62 Jason Farman, Mobile Interface Theory: Embodied Space and Locative Media (New York: Routledge, 2013).

63 Michael Saker, "Foursquare and Identity: Checking-In and Presenting the Self Through Location," New Media \& Society (2016): 4.

64 Evans, Leighton, Locative Social Media: Place in the Digital Age (London: Palgrave Macmillan, 2015).

65 Saker, "Foursquare and Identity."

66 Henriette Cramer, Mattias Rost, and Lars Erik Holmquist, "Performing a Check-In: Emerging Practices, Norms and 'Conflicts' in Location-Sharing Using Foursquare," in Proceedings of the 13th International Conference on Human Computer Interaction with Mobile Devices and Services (ACM, 2011), 57-66.

67 Schwartz, Raz, and Germaine R. Halegoua. "The Spatial Self: Location-Based Identity Performance on Social Media." New Media \& Society 17, no. 10 (2015): 1643-60.

68 Frith, "Communicating Through Location," 890-905.

69 Agar, Constant Touch.

70 Mizuko Ito and Daisuke Okabe, "Intimate Visual Co-Presence" (paper presented at the Ubiquitous Computing Conference, Tokyo, Japan, 2005).

71 Katz and Aakhus, eds. Perpetual Contact.

72 Laursen and Szymanski, "Where Are You?" 314-34.

73 Rich Ling and Scott W. Campbell, eds. The Reconstruction of Space and Time: Mobile Communication Practices (New Brunswick, NJ: Transaction Publishers, 2010).

74 Ling and Yttri, "10 Hyper-Coordination,” 139-169.

75 Boyd, Danah M., "Friendster and Publicly Articulated Social Networking," in Proceedings of the Twenty-Second Annual SIGCHI Conference on Human Factors in Computing Systems. (New York: ACM Press).

76 Nicole B. Ellison, "Social Network Sites: Definition, History, and Scholarship," Journal of Computer-Mediated Communication 13, no. 1 (2007): 210-30.

77 Alice E. Marwick, "'I'm a Lot More Interesting than a Friendster Profile': Identity Presentation, Authenticity and Power in Social Networking Services," Association of Internet Researchers 18 (2005), 6.

78 Amanda Lenhart and Mary Madden, "Teens, Privacy, and Online Social Networks." Pew Internet and American Life Project 18 (2007).

79 Ellison, "Social Network Sites," 210-30.

80 Nicole L. Muscanell and Rosanna E. Guadagno, "Make New Friends or Keep the Old: Gender and Personality Differences in Social Networking Use," Computers in Human Behavior 28, no. 1 (2012): 107-12.

81 David Silverman. Interpreting Qualitative Data: Methods for Analyzing Talk, Text and Interaction (London: Sage, 2006). 


\section{Amps}

82 Nigel King and Christine Horrocks, Interviews in Qualitative Research (Los Angeles: Sage, 2010), 29.

83 Colin Robinson, Real World Research: A Resource for Social Scientists and Practitioner-Researchers (John Wiley \& Sons, 2002), 273.

84 Bert Klandermans and Suzanne Staggenborg, eds. Methods of Social Movement Research. Vol. 16. (University of Minnesota Press, 2002), 110.

85 Klandermans and Staggenborg, eds. Social Movement Research, 110.

86 King and Horrocks, Interviews in Qualitative Research, 142.

87 Sutko and de Souza e Silva, "Location-Aware Mobile Media," 807-23.

88 Frith, "Communicating Through Location," 896.

89 Frith, "Communicating Through Location," 899.

90 Ling, The Mobile Connection.

91 Evans, Locative Social Media.

92 Ling and Yttri, "10 Hyper-Coordination," 139-169.

93 Ling, The Mobile Connection.

94 Ling and Yttri, "10 Hyper-Coordination," 139-169.

95 Humphreys, "Mobile Social networks and Social Practice," 353.

96 Deborah Lupton, The Quantified Self (John Wiley \& Sons, 2016), 40.

97 Ling and Yttri, "10 Hyper-Coordination," 6.

98 Humphreys, "Mobile Social Networks and Social Practice, 341-60.

99 Humphreys, "Mobile Social Networks and Urban Public Space, 763-78.

100 Frith, "Communicating Through Location," 890-905.

101 Frith, "Communicating Through Location," 890-905.

102 Humphreys, "Mobile Social Networks and Social Practice," 341-60.

103 Humphreys, "Mobile Social Networks and Urban Public Space, 763-78.

104 Ibid.,774.

105 Adriana de Souza e Silva and Jordan Frith, "Locational Privacy in Public Space," 505.

106 De Lange and de Waal. "Owning the City."

107 Frith, "Communicating Through Location," 890-905.

108 Zizi Papacharissi, A Private Sphere: Democracy in a Digital Age (Polity, 2010).

109 Lawrence Lessig, Code: And Other Laws of Cyberspace (Basic Books, 1999).

110 Papacharissi, A Private Sphere, 46-7.

111 Sutko and de Souza e Silva, "Location-Aware Mobile," 819.

112 Muscanell and Guadagno, "Make New Friends," 107-112.

113 Frith, "Communicating Through Location," 890-905.

114 Bertel, "'Why Would You Want To Know?," 1.

115 Frith, Smartphones as Locative Media.

116 Susan Elizabeth Ryan, Garments of Paradise: Wearable Discourse in the Digital Age (MIT Press, 2014).

\section{Bibliography}

Agar, Jon. Constant Touch: A Global History of the Mobile Phone. Cambridge: Icon Books Ltd., 2013. 


\section{Amps}

Axhausen, Kay W., John Urry, and Jonas Larsen. Mobilities, Networks, Geographies. Farnham: Ashgate Publishing, Ltd., 2012.

Bertel, Troels Fibæk. “'Why Would You Want to Know?' The Reluctant Use of Location Sharing via Check-Ins on Facebook among Danish Youth." Convergence 22, no. 2 (2016): 162-76.

Boyd, Danah M. "Friendster and Publicly Articulated Social Networking." (2004): 1279-82.

Cramer, Henriette, Mattias Rost, and Lars Erik Holmquist. "Performing a Check-In: Emerging Practices, Norms and 'Conflicts' in Location-Sharing Using Foursquare." In Proceedings of the 13th International Conference on Human Computer Interaction with Mobile Devices and Services, pp. 57-66, ACM, 2011.

De Gournay, Chantal. "12 Pretense of Intimacy in France." In Perpetual Contact: Mobile Communication, Private Talk, Public Performance, edited by James E. Katz and Mark Aakhus Cambridge University Press, 2002.

De Lange and De Waal. "Owning the City: New Media and Citizen Engagement in Urban Design.” First Monday 18, no. 11 (2013), n.p, accessed October 26, 2017, doi: http://firstmonday.org/article/view/4954/3786.

De Souza e Silva, Adriana. "From Cyber to Hybrid," Mobile Technologies as Interfaces of Hybrid Spaces." Space and Culture 9, no. 3 (2006): 261-78.

De Souza e Silva, Adriana, and Jordan Frith. "Locational Privacy in Public Spaces: Media Discourses on Location-Aware Mobile Technologies." Communication, Culture \& Critique 3, no. 4 (2010): 503-25.

Ellison, Nicole B. "Social Network Sites: Definition, History, and Scholarship." Journal of Computer-Mediated Communication 13, no. 1 (2007): 210-30.

Evans, Leighton. Locative Social Media: Place in the Digital Age. London: Palgrave Macmillan, 2015

Evans, Leighton, and Michael Saker. Location-Based Social Media: Space, Time and Identity. Berlin: Springer, 2017.

Farman, Jason. Mobile Interface Theory: Embodied Space and Locative Media. Routledge, 2013.

Foursquare Corporation. “About Us.” Accessed April 8, 2016, https://foursquare. com/about

Frith, Jordan. "Splintered space: Hybrid spaces and differential mobility." Mobilities 7, no. 1 (2012): 131-49.

Frith, Jordan. "Turning Life into a Game: Foursquare, Gamification, and Personal Mobility.” Mobile Media \& Communication 1, no. 2 (2013): 248-62.

Frith, Jordan. "Communicating Through Location: The Understood Meaning of the Foursquare Check-In." Journal of Computer-Mediated Communication 19, no. 4 (2014): 890-905.

Frith, Jordan. Smartphones as Locative Media. John Wiley \& Sons, 2015.

Frith, Jordan, and Jason Kalin. "Here, I Used to Be: Mobile Media and Practices of Place-Based Digital Memory.” Space and Culture 19, no. 1 (2016): 43-55.

Gergen, K. J. (2002). The Challenge of Absent Presence. In Perpetual Contact: Mobile Communication, Private Talk, Public Performance, edited by James E. Katz and Mark Aakhus, 227-41. Cambridge University Press, 2002. 


\section{Amps}

Gordon, Eric, and Adriana de Souza e Silva. Net Locality: Why Location Matters in a Networked World. Malden, MA: John Wiley \& Sons, 2011.

Hjorth, Larissa. "Being Real in the Mobile Reel: A Case Study on Convergent Mobile Media as Domesticated New Media in Seoul, South Korea.” Convergence 14, no. 1 (2008): 91-104.

Humphreys, Lee. "Mobile Social Networks and Social Practice: A Case Study of Dodgeball." Journal of Computer-Mediated Communication 13, no. 1 (2007): 341-60.

Humphreys, Lee. "Mobile Social Networks and Urban Public Space." New Media \& Society 12, no. 5 (2010): 763-78.

Humphreys, Lee, and Tony Liao. "Foursquare and the Parochialization of Public Space." First Monday 18, no. 11 (2013).

Ito, Mizuko, and Daisuke Okabe. "Intimate Visual Co-presence." In 2005 Ubiquitous Computing Conference. 2005.

Katz, James E., and Mark Aakhus, eds. Perpetual Contact: Mobile Communication, Private Talk, Public Performance. Cambridge: Cambridge University Press, 2002.

King, Nigel and Christine Horrocks. Interviews in Qualitative Research. Los Angeles: Sage, 2010.

Klandermans, Bert, and Suzanne Staggenborg, eds. Methods of Social Movement Research. Vol. 16. University of Minnesota Press, 2002.

Laursen, Ditte, and Margaret H. Szymanski. "Where Are You? Location Talk in Mobile Phone Conversations." Mobile Media \& Communication 1, no. 3 (2013): 314-34.

Lenhart, Amanda, and Mary Madden. "Teens, Privacy \& Online Social Networks." Pew Internet and American Life Project Report18, 2007.

Lessig, Lawrence. Code and Other Laws of Cyberspace. Bacik Books, 1999.

Licoppe, Christian. "'Connected' presence: the emergence of a new repertoire for managing social relationships in a changing communication technoscape." Environment and planning D: Society and space 22, no. 1 (2004): 135-56.

Licoppe, Christian, and Yoriko Inada. "Geolocalized Technologies, LocationAware Communities, and Personal Territories: The Mogi Case." Journal of Urban Technology 15, no. 3 (2008): 5-24.

Lindqvist, Janne, Justin Cranshaw, Jason Wiese, Jason Hong, and John Zimmerman. "I'm the Mayor of My House: Examining Why People Use Foursquare - A SocialDriven Location Sharing Application." In Proceedings of the SIGCHI Conference on Human Factors in Computing Systems, 2409-18. ACM, 2011.

Ling, Rich. The Mobile Connection: The Cell Phone's Impact on Society. Morgan Kaufmann, 2004.

Ling, Rich, and Scott W. Campbell, eds. The Reconstruction of Space and Time: Mobile Communication Practices. New Brunswick, NJ: Transaction Publishers, 2010.

Ling, Richard and Birgitte Yttri. 10 Hyper-Coordination via Mobile Phones. In Perpetual Contact: Mobile Communication, Private Talk, Public Performance, edited by James E. Katz and Mark Aakhus, 139-69, Cambridge University Press, 2002. 


\section{Amps}

Lupton, Deborah. The Quantified Self. John Wiley \& Sons, 2016.

Marwick, Alice E. "'I'm a Lot More Interesting than a Friendster Profile': Identity Presentation, Authenticity and Power in Social Networking Services." Association of Internet Researchers 18 (2005).

Muscanell, Nicole L., and Rosanna E. Guadagno. "Make new friends or keep the old: Gender and personality differences in social networking use." Computers in Human Behavior 28, no. 1 (2012): 107-12.

Papacharissi, Zizi. A Private Sphere: Democracy in a Digital Age. Polity, 2010.

Rheingold, Howard, and Anthony Weeks. Net Smart: How to Thrive Online. Cambridge, MA; MIT Press, 2012.

Robson, Colin, and Kieran McCartan. Real World Research. John Wiley \& Sons, 2016.

Ryan, Susan Elizabeth. Garments of Paradise: Wearable Discourse in the Digital Age. Cambridge, MA: MIT Press, 2014.

Saker, Michael. "Foursquare and Identity: Checking-In and Presenting the Self through Location." New Media \& Society (2016): 1461444815625936.

Saker and Evans. "Locative Mobile Media and Time: Foursquare and Technological Memory." First Monday 21, no. 2 (2016).

Schwartz, Raz, and Germaine R. Halegoua. "The Spatial Self: Location-Based Identity Performance on Social Media." New Media \& Society (2014).

Silverman, David. Interpreting Qualitative Data: Methods for Analyzing Talk, Text and Interaction. London: Sage, 2006.

Simmel, Georg. The Metropolis and Mental Life. In Simmel on Culture, edited by David Frisby and Mike Featherstone, 177. London: Sage.

Stavrinos, Despina, Katherine W. Byington, and David C. Schwebel. "Distracted Walking: Cell Phones Increase Injury Risk for College Pedestrians." Journal of Safety Research 42, no. 2 (2011): 101-107.

Sutko, Daniel M., and Adriana de Souza e Silva. "Location-Aware Mobile Media and Urban Sociability.” New Media \& Society 13, no. 5 (2011): 807-23.

Townsend, Anthony M. "Life in the Real-Time City: Mobile Telephones and Urban Metabolism." Journal of Urban Technology 7, no. 2 (2000): 85-104.

Weilenmann, Alexandra. "“I Can't Talk Now, I'm in a Fitting Room": Formulating Availability and Location in Mobile-Phone Conversations." Environment and Planning A 35, no. 9 (2003): 1589-1605.

Wellman, Barry. "Little Boxes, Glocalization, and Networked Individualism." In Kyoto Workshop on Digital Cities, ed. Makoto Tanabe, Peter van den Besselaar, and Toru Ishida, 10-25. Berlin Heidelberg: Springer, 2001.

Wilken, Rowan. "Locative Media: From Specialized Preoccupation to Mainstream Fascination." Convergence 18, no. 3 (2012): 243-7.

Wilken, Rowan, and Gerard Goggin, eds. Mobile Technology and Place. London: Routledge, 2013.

Willig, Carla. Introducing Qualitative Research in Psychology. Maidenhead, Berks: McGraw-Hill Education, 2013. 